\title{
Resin Gum Dosage Form
}

National Cancer Institute

\section{Source}

National Cancer Institute. Resin Gum Dosage Form. NCI Thesaurus. Code C42978.

A semi-solid composed of a mixture of gum and a plant based hydrocarbon. 